\title{
Finite element bending behaviour of discretely delaminated composite conoidal shell roofs under concentrated load
}

\author{
Suman Kumari ${ }^{1}$, Dipankar Chakravorty ${ }^{2 *}$ \\ ${ }^{1}$ Department of Civil Engineering, Jadavpur University \\ Kolkata-700 032, INDIA: upadhyay.suman@gmail.com \\ ${ }^{2}$ Department of Civil Engineering, Jadavpur University \\ Kolkata-700 032, INDIA: dchakravorty_jdvu@yahoo.com \\ *Corresponding Author's e-mail: dchakravorty_jdvu@yahoo.com
}

\begin{abstract}
Laminated composites are increasingly getting used in civil engineering structural components including shell structural units due to their light weight, high specific strength and stiffness properties. One of the major causes of failure in these laminated composites is delamination resulting from the interlaminar debonding between the laminae forming the laminate. A review of literature that exists on composite shells reveals that the research reports on delaminated shells are very few in numbers. Among the shell forms used popularly in the industry, the conoidal ones are aesthetically pleasing and also easy to fabricate being singly ruled surfaces. To use these conoids widely with confidence, behaviour of these forms with possible delamination damage has to be studied in depth. Hence, in this paper, a study on bending behaviour of delaminated composite conoidal shells is done. An eight noded isoparametric element with five degrees of freedom per node is used together with Sanders' strain displacement relationships. To satisfy the compatibility of displacements and rotations along the crack edges a multipoint constraint algorithm is incorporated. Benchmark problems are solved to validate the present approach and a wide variety of composite conoidal shell problems with midplane delaminations are solved by varying the stacking sequence, extents of delamination and boundary conditions under central point load. The results are critically discussed to arrive at conclusions of engineering significance highlighting particularly the differences in behaviour between undamaged and damaged shells.
\end{abstract}

Keywords: Laminated composite, conoidal shells, delamination, finite element method, roofs, concentrated load.

\section{Introduction}

Composite conoidal shells (Figure 1) are used widely as roofing units to cover large column-free areas because they provide ease of fabrication being single ruled surfaces, look aesthetically elegant and also allow entry of sufficient daylight through inclined sunrays. Over the course of time this shell form became very popular to engineers due to a number of advantages it offers, and started drawing the attention of a number of researchers. Research works on these shell forms are continuing from the second half of last century till date covering static and dynamic aspects. A number of research papers appear in the literature about the different aspects of conoidal shells and in very recent papers Das and Chakravorty $(2007,2008)$ reported bending and vibration behaviour of composite conoids for different boundary conditions using finite element approach.

These laminated composite shells are prone to delamination damage during their service life, which may occur due to manufacturing defects, sudden impacts, overloading, particularly of concentrated forces, etc. It is very important to analyze the behaviour of such damaged roofing units under external loading conditions because delamination or damage growth beyond a limiting size can result in strength deterioration and may cause total collapse of structure.

A plate finite element was developed by Gim (1994) for analysis of delaminated composite plates. This plate modeling can be modified for bending analysis of delaminated composite shells on square planform. A general theory of laminated anisotropic shells of arbitrary shape and curvature was founded by Librescu et al. (2000) in which the effect of interfacial damage induced by the imperfect bonding between the constituent laminae was incorporated. Tafreshi (2004a, 2004b) reported computational 
modeling of delamination in isotropic and composite cylindrical shells using three dimensional finite elements. The influences of delamination size, orientation and through-the-width position on buckling loads of composite cylindrical shells were studied. Krishnamurthy et al. (2001) studied response of impact loading and resulting damage of cylindrical composite shells accounting for large deformations in curved panels including full cylinders by finite element method. Acharyya et al. 2008 used a finite element method for the study of bending behaviour of partially delaminated shallow cylindrical composite shells subjected to uniformly distributed load with various practical boundary conditions. In some recent publications Acharyya et al. (2009a, 2009b) studied the bending characteristics of delaminated cylindrical shells and the natural vibrations of delaminated composite clamped cylindrical shell roofs respectively using finite element method with centrally located midplane delamination for various delamination areas, stacking sequences and curvatures.

From the available research reports it is clear that work on delaminated composite structures has been taken up by some researchers. But most of the reports are about composite plates. In the area of delaminated composite shells a few reports that have come up are for static and dynamic behaviour of cylindrical and spherical shells only. The authors find no work has been reported in the field of delaminated composite conoids, which are very important industrial roofing units used extensively in the industry. Hence, in the present paper, a study of the bending behaviour of delaminated composite conoidal shells is carried out under concentrated load with various boundary conditions and stacking sequences.

\section{Mathematical Formulation}

2.1 Finite Element Formulation: An eight noded isoparametric curved quadratic shell element with five degrees of freedom $u, v, w, \alpha, \beta$ at each node (displacements along $x, y$ and $z$ axes and rotations about $y$ and $x$ axes) is used in the present shell analysis. The element displacements are expressed in terms of their nodal values given by

$$
u=\sum_{i=1}^{8} N_{i} u_{i}, \quad v=\sum_{i=1}^{8} N_{i} v_{i}, \quad w=\sum_{i=1}^{8} N_{i} w_{i}, \quad \alpha=\sum_{i=1}^{8} N_{i} \alpha_{i}, \quad \beta=\sum_{i=1}^{8} N_{i} \beta_{i}
$$

where $N_{i}$ 's are the shape functions given by

$$
\begin{aligned}
& N_{i}=\frac{1}{4}\left(1+\xi \xi_{i}\right)\left(1+\eta \eta_{i}\right)\left(\xi \xi_{i}+\eta \eta_{i}-1\right), \quad i=1,2,3,4, \\
& N_{i}=\frac{1}{2}\left(1+\xi \xi_{i}\right)\left(1-\eta^{2}\right), \quad i=5,7 \\
& N_{i}=\frac{1}{2}\left(1+\eta \eta_{i}\right)\left(1-\xi^{2}\right), \quad i=6,8 .
\end{aligned}
$$

The generalized displacement vector $[u]$ of an element is expressed in terms of shape functions $[N]$ and nodal degrees of freedom $\left\{d_{e}\right\}$ as

$$
[u]=[N]\left\{d_{e}\right\}
$$

2.2 Modeling of Undelaminated Shell: The undelaminated region is modeled by shell element 1 of thickness $h$ (Figure 3). For this we consider a laminated composite conoidal shell (Figure 1.) of uniform thickness $h$ and radius of curvature $R_{y}$ along y-direction and twist radius of curvature $R_{x y}$. Keeping the total thickness same, the thickness may consist of any number of thin laminae each of which may be arbitrarily oriented at an angle $\theta$ with reference to the $x$-axis of the co-ordinate system. In the present study $R_{y}$ and $R_{x y}$ can be obtained from partial derivatives of surface equation $z=f(x, y)$ and

$$
\frac{1}{R_{x y}}=\frac{\partial^{2} z}{\partial x \partial y} \text { and } \frac{1}{R_{y}}=\frac{\partial^{2} z}{\partial y^{2}}
$$




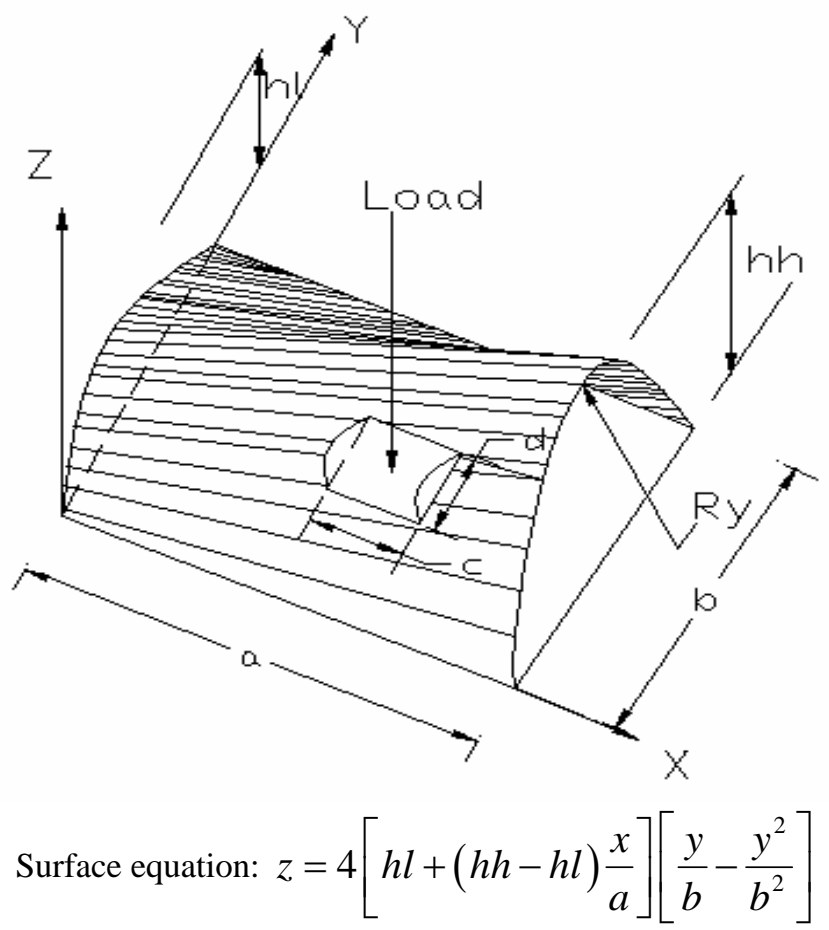

Figure 1. Conoidal shell with delamination zone and centrally applied concentrated load

The strain-displacement relations, elasticity matrix and systematic development of element stiffness matrix of undelaminated portion used here are the same as were used by Das and Chakravorty (2007).

The constitutive equations for the shell are given by (refer list of notations):

$\{F\}=[D]\{\varepsilon\}$

where [D] is elasticity matrix of undelaminated composite shell given by

$[D]=\left[\begin{array}{lll}A & B & 0 \\ B & A & 0 \\ 0 & 0 & S\end{array}\right]$

where A, B and S are the axial, bending and shear components respectively.

For the undelaminated portion 1 (Figure 2) of partially delaminated thin shells having $n$ numbers of layers or laminae, the inplane stress resultants $\{N\}_{1}$, the moment resultants $\{M\}_{1}$ and the transverse shear resultants $\{Q\}_{1}$ can be expressed as follows:

$$
\begin{aligned}
& \{N\}_{1}=[A]_{1}\left\{\varepsilon^{0}\right\}_{1}+[B]_{1}\{\kappa\}_{1}, \\
& \{M\}_{1}=[B]_{1}\left\{\varepsilon^{0}\right\}_{1}+[D]_{1}\{\kappa\}_{1}, \\
& \{Q\}_{1}=[S]_{1}\{\gamma\}_{1} .
\end{aligned}
$$

where $\{\varepsilon\}$ and $\{\gamma\}$ are the direct and shear strains in midplane and $\{\kappa\}$ denotes the changes of shell curvature due to loading [Refer Das and Chakravorty (2007)]. Suffix 1 is used in equations (6) to denote undelaminated portion (see Figure 3).

2.3 Modeling with multiple delamination: A typical composite laminate with $n$ layers and p number of delaminations (Figure 2) is considered here for the delamination modeling. Figure 3 shows cross-sectional view of portions of a delamination crack tip, where nodes of three shell elements meet together to form a common node. Portion 1 is undelaminated shell region. The delaminated region is modeled by shell elements 2 and 3 whose interface contains the considered delamination. 


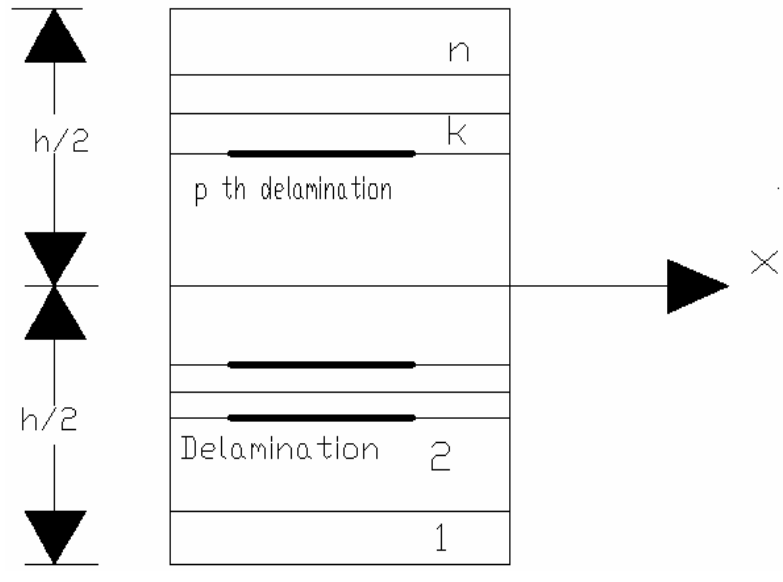

Figure 2. Laminate geometry with multiple delaminations

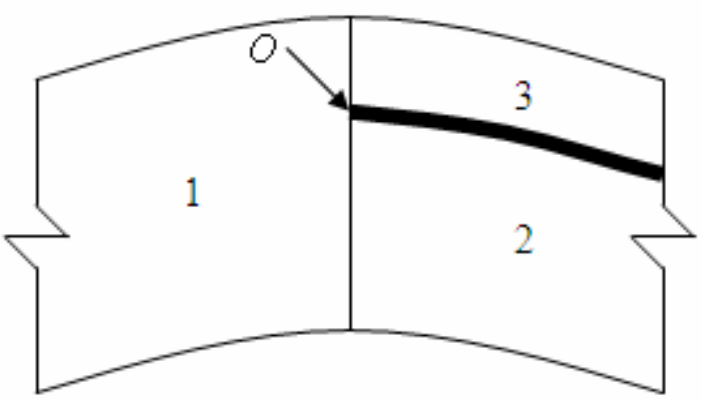

Figure 3. Portions of a delamination crack tip

For the delaminated portions 2 and 3, in-plane strains, curvatures and transverse shear strains are identical at the crack tip i.e., at point $\mathrm{O}$ of Figure 3 as suggested by Gim (1994). Thus, the relation of midplane strains between portions 1, 2 and 3 can be written in following manner.

$$
\left\{\varepsilon^{0}\right\}_{l}=\left\{\varepsilon^{0}\right\}_{1}+z_{l}^{0}\{\kappa\}_{1}
$$

In equation (7) suffix $l$ is used to denote delaminated portions 2 and 3.

Using equation (7) the inplane nodal forces and moments of portions 2 and 3 can be expressed as

$$
\begin{aligned}
& \{N\}_{l}=[A]_{l}\left\{\varepsilon^{0}\right\}_{1}+\left(z_{l}^{0}[A]_{l}+[B]_{l}\right)\{\kappa\}_{1}, \\
& \{M\}_{l}=[B]_{l}\left\{\varepsilon^{0}\right\}_{1}+\left(z_{l}^{0}[B]_{l}+[D]_{l}\right)\{\kappa\}_{1}, \\
& \{Q\}_{l}=[S]_{l}\{\gamma\}_{1} .
\end{aligned}
$$

The constitutive equations for the delaminated shell are given by (refer list of notations):

$$
\{F\}=[D]_{l}\{\varepsilon\}
$$

where

$$
\begin{aligned}
& \{F\}=\left\{\begin{array}{llllllll}
N_{x} & N_{y} & N_{x y} & M_{x} & M_{y} & M_{x y} & Q_{x} & Q_{y}
\end{array}\right\}^{T} \\
& {[D]_{l}=\left[\begin{array}{ccc}
A_{i j} & z_{l}^{0} A_{i j}+B_{i j} & 0 \\
B_{i j} & z_{l}^{0} B_{i j}+D_{i j} & 0 \\
0 & 0 & S_{i j}
\end{array}\right]} \\
& \{\varepsilon\}=\left\{\begin{array}{llllllll}
\varepsilon_{x}^{0} & \varepsilon_{y}^{0} & \gamma_{x y}^{0} & \kappa_{x} & \kappa_{y} & \kappa_{x y} & \gamma_{x z}^{0} & \gamma_{y z}^{0}
\end{array}\right\}^{T}
\end{aligned}
$$

In equation $(10)[D]_{l}$ is elasticity matrix of delaminated shell of $\mathrm{l}^{\text {th }}$ sublaminate.

$$
\left[A_{i j}\right]_{l}=\int_{-h_{l} / 2+z_{l}^{0}}^{h_{l} / 2+z_{l}^{0}}\left[Q_{i j}\right]_{\text {off }} d z, \quad\left[B_{i j}\right]_{l}=\int_{-h_{l} / 2+z_{l}^{0}}^{h_{l} / 2+z_{l}^{0}}\left[Q_{i j}\right]_{o f f}\left(z-z_{l}^{0}\right) d z,
$$




$$
\begin{array}{ll}
{\left[D_{i j}\right]_{l}=\int_{-h_{l} / 2+z_{l}^{0}}^{h_{l} / 2+z_{l}^{0}}\left[Q_{i j}\right]_{\text {off }}\left(z-z_{l}^{0}\right)^{2} d z,} & i, j=1,2,6, \\
{\left[S_{i j}\right]_{l}=\int_{-h_{l} / 2+z_{l}^{0}}^{h_{l} / 2+z_{l}^{0}}\left[Q_{i j}\right]_{\text {off }} d z,} & i, j=4,5 .
\end{array}
$$

Here $h_{l}$ is the thickness of the $\mathrm{l}^{\text {th }}$ sublaminate.

To satisfy the compatibility at the delamination crack tip O (see Figure 3) it is assumed that the transverse displacements, rotations and the inplane displacements of all three portions 1, 2 and 3 at the crack tip are assumed to be equal. Using the above assumptions and combining equations (7) and (8) relation between the nodal forces and moment of portions 1, 2 and 3 can be written as

$$
\begin{aligned}
& \{N\}=\{N\}_{1}=\{N\}_{2}+\{N\}_{3}, \\
& \{M\}=\{M\}_{1}=\{M\}_{2}+\{M\}_{3}+z_{2}^{0}\{N\}_{2}+z_{3}^{0}\{N\}_{3}, \\
& \{Q\}=\{Q\}_{1}=\{Q\}_{2}+\{Q\}_{3} .
\end{aligned}
$$

The element stiffness matrix can be derived from the above force-strain relationship. The element stiffness matrix and load vectors are assembled to get the global stiffness matrix $[K]$ and global load vector $\{P\}$ respectively. The basic problem of static equilibrium takes the form

$$
[K]\{\delta\}=\{P\}
$$

\section{Numerical Problems}

In the present research work three benchmark problems, available in the literature, are solved to establish the validity of the formulation. The details of the benchmark problems are as follows:

Benchmark problem 1: Deflection of simply supported plates on square planform under centrally applied concentrated load solved by Reddy (1997). (see Table 1)

Benchmark problem 2: Maximum non-dimensional downward deflections of conoidal shells for $\left(0^{0} / 90^{\circ}\right)$ and $\left(+45^{0} /-45^{0} /+45^{0}\right)$ laminations under uniformly distributed load with clamped and simply supported boundary conditions as reported by Das et al. (2007). (Refer Table 2)

Benchmark problem 3: Maximum transverse non-dimensional deflections of cylindrical shells centrally delaminated at mid thickness for $\left(0^{0} / 90^{\circ}\right)$ and $\left(+45^{0} /-45^{0} /+45^{0}\right)$ laminations and different boundary conditions under uniformly distributed load obtained by Acharyya et al. (2009) (see Table 3)

Various other problems which are authors' own are solved to study the bending behaviour of delaminated composite conoidal shells under centrally applied concentrated load. The authors have considered mid thickness delamination located centrally in plan. To study the bending behaviour of delaminated conoidal shells under concentrated load, the authors have considered the following parametric variations of graphite-epoxy composite shells:

1. Three different boundary conditions of corner point supported, simply supported and clamped edges are taken into consideration.

2. Eight different types of stacking sequences are considered, which include cross and angle plies. Both antisymmetric and symmetric cases are taken up.

3. The area of single central mid surface delamination zone is varied from zero $(c / a=0)$ to $56.25 \%(c / a=0.75)$ of total plan area of the shell. The planform of shell is square $(a / b=1)$ and delaminated zone $(c \times d)$ is centrally located along the depth.

\section{Results and Discussion}

The results of first benchmark problem obtained by Reddy (1997) and present formulation are furnished in Table 1. It shows that the results obtained by present approach are in good agreement with the results of Reddy (1997). This proves the correct inclusion 
of concentrated load model in the present formulation. In this problem the authors have taken liberty to use their formulation developed for composite shells to composite plates case by assigning very high value to $R_{y}$ and $R_{x y}$.

It is evident from values of Table 2 that results obtained by present approach match closely with the results obtained by Das et al. (2007). This verification proves the correctness of conoidal shell formulation.

Table 1. Maximum transverse non-dimensional downward deflections $\left(\bar{w} \times 10^{2}\right)$ of simply supported composite plates under concentrated load

\begin{tabular}{ccc}
\hline Lamination & Reddy (1997) & Present approach \\
\hline$\left(0^{0} / 90^{\circ}\right)$ & 4.666 & 4.679 \\
$\left(90^{0} / 0^{\circ}\right)$ & 4.666 & 4.679 \\
$\left(0^{0} / 90^{\circ}\right)_{2}$ & 2.210 & 2.227 \\
$\left(0^{0} / 90^{\circ}\right)_{4}$ & 1.953 & 1.971 \\
\hline Note: $E_{11} / E_{22}=25, G_{12}=G_{13}=0.5 E_{22}, G_{23}=0.2 E_{22}, v_{12}=0.25, a / b=1, a / h=100$.
\end{tabular}

Table 2. Maximum transverse non-dimensional downward deflections $\left(\bar{w} \times 10^{4}\right)$ of composite conoidal shells for different laminations and boundary conditions

\begin{tabular}{ccccc}
\hline \multirow{2}{*}{ Stacking Sequences } & \multicolumn{2}{c}{ Clamped } & \multicolumn{2}{c}{ Simply supported } \\
\cline { 2 - 4 } & Das(2007) & Present & Das(2007) & Present \\
\hline$\left(0^{0} / 90^{\circ}\right)$ & -0.319 & -0.319 & -5.63 & -5.63 \\
$\left(+45^{0} /-45^{\circ} /+45^{\circ}\right)$ & -0.629 & -0.620 & -2.41 & -2.38 \\
\hline
\end{tabular}

Note: $E_{11}=25 E_{22}, G_{12}=G_{13}=0.5 E_{22}, G_{23}=0.2 E_{22}, v_{12}=0.25, a / b=1, a / h=100, h l / h h=0.25$.

The results of third benchmark problem are presented in Table 3. The authors have assigned high value of $R_{x y}$ and constant value of $R_{y}$ to model a cylindrical shell. Table 3 shows a close agreement between the present results and those obtained by Acharyya et al. (2009). Hence the correctness of delaminated composite shell formulation in the present finite element code is also established.

Table 3. Maximum transverse non-dimensional downward deflections $\left(\times 10^{-4}\right)$ of composite delaminated cylindrical shells for different laminations and boundary conditions

\begin{tabular}{cccccccc}
\hline \multirow{2}{*}{ Stacking Sequences } & \multirow{2}{*}{ c/a } & \multicolumn{2}{c}{ Corner-supported } & \multicolumn{2}{c}{ Simply supported } & \multicolumn{2}{c}{ Clamped } \\
\cline { 2 - 7 } & & Acharyya(2009) & Present & Acharyya(2009) & Present & Acharyya(2009) & Present \\
\hline \multirow{3}{*}{$\left(0^{\circ} / 90^{\circ}\right)$} & 0 & -89.440 & -89.440 & -24.576 & -24.575 & -1.324 & -1.323 \\
& 0.25 & -88.838 & -88.837 & -25.228 & -25.227 & -2.118 & -2.117 \\
& 0.5 & -86.532 & -86.530 & -25.541 & -25.540 & -1.765 & -1.760 \\
& 0.75 & -85.207 & -85.206 & -25.344 & -25.344 & -1.098 & -1.095 \\
$\left(+45^{\circ} /-45^{\circ} /+45^{\circ}\right)$ & 0 & -39.504 & -39.505 & -3.603 & -3.608 & -2.210 & -2.210 \\
& 0.25 & -42.328 & -42.328 & -3.672 & -3.668 & -2.402 & -2.405 \\
& 0.5 & -49.566 & -49.567 & -4.822 & -4.823 & -2.276 & -2.278 \\
& 0.75 & -81.169 & -81.168 & -7.716 & -7.895 & -2.218 & -2.220 \\
\hline
\end{tabular}

Note: $E_{11}=25 E_{22}, G_{12}=G_{13}=0.5 E_{22}, G_{23}=0.2 E_{22}, v_{12}=0.25, a / b=1, c=d, a / h=100$.

Tables 4-6 contain the results of maximum transverse non-dimensional downward deflections of undamaged and delaminated shells by varying the number of laminae from two to four, the total thickness of the laminate remaining same $(h)$ for three different boundary conditions respectively.

4.1 Behaviour of corner point supported shells under point load - Undamaged and delaminated

Results of corner point supported boundary conditions are furnished in Table 4. It is evident from the table that maximum transverse non-dimensional downward deflections consistently increase with increase in $c / a$ ratio in almost all the cases of 
laminations considered here. For example in case of $\left(0^{0} / 90^{\circ}\right)$ laminate the deflections are $13.35 \%, 17.80 \%$ and $22.25 \%$ more for $c / a=0.25,0.5$ and 0.75 respectively with respect to the corresponding deflection of undelaminated shell. This behaviour is quite expected as delamination damage brings about a decrease in stiffness. But for few stacking sequences like $\left(0^{\circ} / 90^{\circ} / 0^{\circ}\right)$, $\left(0^{\circ} / 90^{\circ}\right)_{s}$ and $\left(+45^{0} /-45^{\circ}\right)_{s}$ the above trend is not observed. To know the details of such exceptional cases deflection contours with different extents of delamination for these stacking sequences are studied. Out of these, the deflection profiles for $\left(0^{0} / 90^{0} / 0^{0}\right)$ and $\left(+45^{0} /-45^{0}\right)_{s}$ are presented in Figure 4 and Figure 5 respectively. The deflection profiles show that although the deflection value under the point load may undergo a decrease when delamination area grows in size but the average deflection of the delaminated zone undergoes an increase. There is a total change in the appearance of the deflected shape in the damaged zone, which assumes a depressed basin like configuration. The ratio of deflection of a damaged shell to that of the corresponding undamaged one is designated as $\mathrm{k}$ henceforth and variation of this ratio $\mathrm{k}$ with $c / a$ is represented in graphical form as Figure 6.

\subsubsection{Cross ply vs angle ply shells}

Among undamaged shells, two layered angle ply shell shows higher stiffness than cross ply ones under point load. But for three layered stacking orders, cross ply shell is stiffer than angle ply one. Among two shells roofing units subjected to identical loading condition the one exhibiting lower deflection value shows better performance in terms of static stiffness. On thorough investigation of four layered antisymmetric shells it is found that performance of angle ply shell is better than the cross ply one whereas, for four layered symmetric shells, cross ply shell shows less deflection values than the angle ply one.

Table 4. Maximum transverse non-dimensional downward deflections $\left(\bar{w} \times 10^{2}\right)$ of corner point supported delaminated conoidal shells under concentrated load with different laminations

\begin{tabular}{ccccc}
\hline \multirow{2}{*}{ Stacking sequence } & \multicolumn{5}{c}{$\boldsymbol{c} / \boldsymbol{a}$} \\
\cline { 2 - 5 } $0^{\circ} / 90^{\circ}$ & $\mathbf{0}$ & $\mathbf{0 . 2 5}$ & $\mathbf{0 . 5}$ & $\mathbf{0 . 7 5}$ \\
\hline \multirow{2}{*}{$0^{\circ} / 90^{\circ} / 0^{\circ}$} & -0.764 & -0.866 & -0.900 & -0.934 \\
& $(0.5,0.5)$ & $(0.5,0.5)$ & $(0.5,0.5)$ & $(0.5,0.5)$ \\
$+45^{\circ} /-45^{\circ}$ & -0.404 & -0.833 & -0.641 & -1.204 \\
& $(0.5,0.5)$ & $(0.5,0.5)$ & $(0.5,0.5)$ & $(0.5,0.5)$ \\
$+45^{\circ} /-45^{\circ} /+45^{\circ}$ & -0.734 & -0.816 & -0.865 & -0.926 \\
& $(0.5,0.5)$ & $(0.5,0.5)$ & $(0.5,0.5)$ & $(0.5,0.5)$ \\
$\left(0^{\circ} / 90^{\circ}\right)_{2}$ & -0.513 & -0.757 & -1.033 & -1.548 \\
& $(0.5,0.5)$ & $(0.5,0.5)$ & $(0.5,0.5)$ & $(0.5,0.5)$ \\
$\left(0^{\circ} / 90^{\circ}\right)_{\mathrm{S}}$ & -0.451 & -0.799 & -0.995 & -1.219 \\
& $(0.5,0.5)$ & $(0.5,0.5)$ & $(0.5,0.5)$ & $(0.5,0.5)$ \\
$\left(+45^{\circ} /-45^{\circ}\right)_{2}$ & -0.386 & -1.514 & -1.290 & -1.200 \\
& $(0.5,0.5)$ & $(0.5,0.5)$ & $(0.5,0.5)$ & $(0.5,0.5)$ \\
$\left(+45^{\circ} /-45^{\circ}\right)_{\mathrm{S}}$ & -0.395 & -0.729 & -0.909 & -1.293 \\
& $(0.5,0.5)$ & $(0.5,0.5)$ & $(0.5,0.5)$ & $(0.5,0.5)$ \\
& -0.432 & -0.689 & -1.094 & -0.690 \\
\hline
\end{tabular}

Note: $E_{11}=25 E_{22}, G_{12}=G_{13}=0.5 E_{22}, G_{23}=0.2 E_{22}, v_{12}=0.25, a / b=1, c=d, a / h=100, h l / h h=0.25$.

Values in the parentheses indicate the location $(\bar{x}=x / a, \bar{y}=y / b)$ of maximum downward deflection in each case.

When we study the relative behaviour of damaged cross and angle ply shells under concentrated load then, it is observed that two layered angle ply shell performs better than cross ply one for all the cases of delamination. In case of three layered laminates, cross 
ply shells show $37.94 \%$ and $22.22 \%$ lower deflection values than corresponding angle ply ones for $c / a=0.5$ and 0.75 respectively. Among four layered shells, performance of angle ply shell is better than the cross ply one, by and large, excluding $\left(+45^{0} /-45^{0}\right)_{2}$ lamination with extent of damaged area $c / a=0.75$.

This observation clearly indicates that in case of undamaged shells if comparison is made between cross and angle ply laminations under centrally applied point load, then for antisymmetric laminates angle ply show better results, whereas for symmetric lamination cross ply shows better performance. Among damaged shells it can be concluded that overall performance of angle ply shells is consistently better than the cross ply ones.
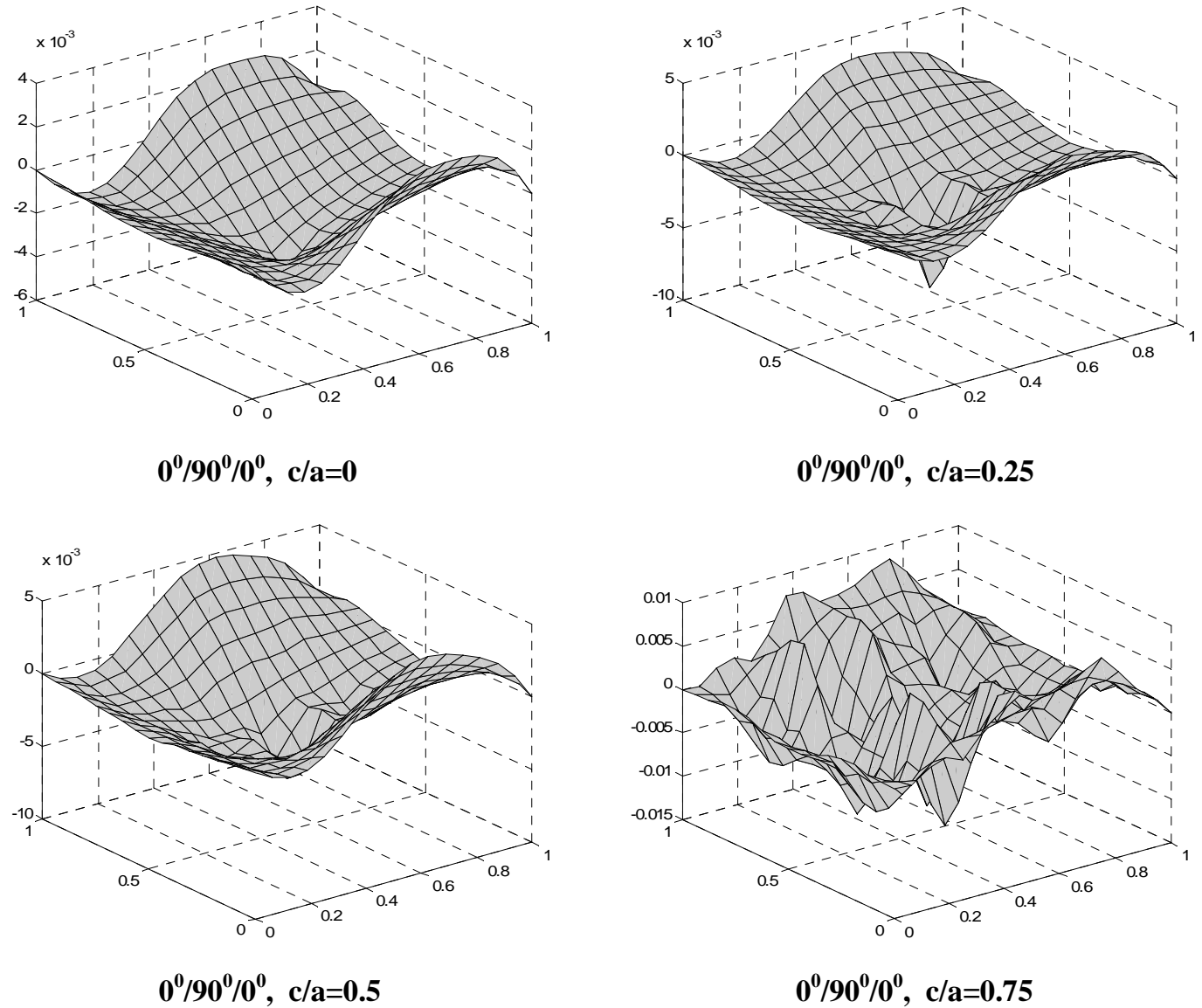

Figure 4. Deflection profile of corner point supported $\left(0^{0} / 90^{0} / 0^{0}\right)$ shell with different extent of delaminations

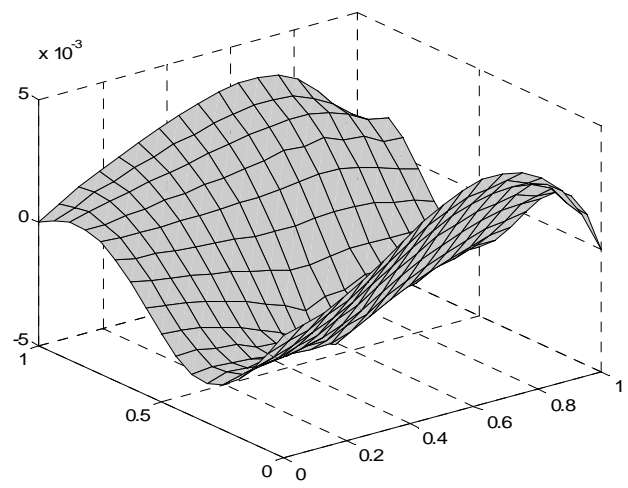

$\left(+45^{0} /-45^{0}\right)_{s}, \mathrm{c} / \mathrm{a}=0$

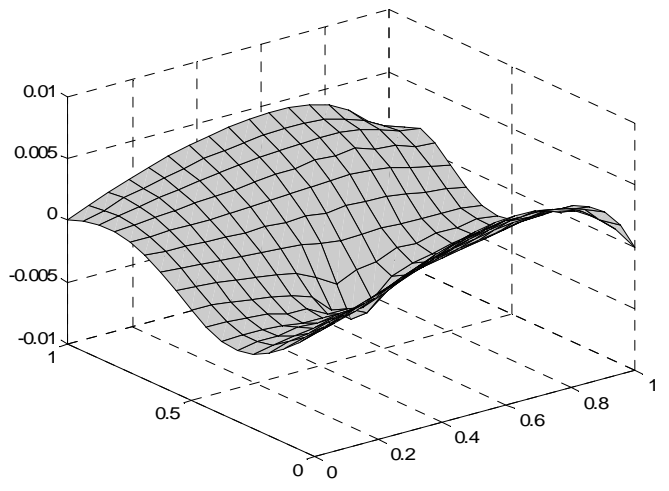

$\left(+45^{0} /-45^{0}\right)_{s}, c / a=0.25$ 

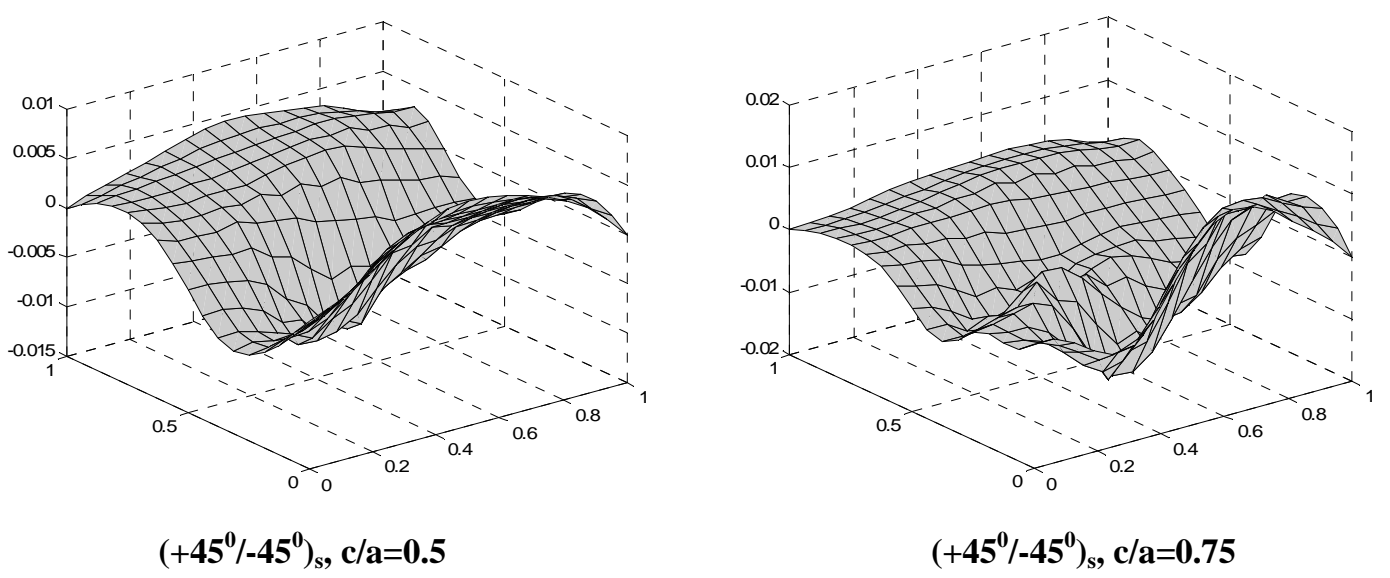

Figure 5. Deflection profile of corner point supported $\left.(\mathbf{+ 4 5} /-\mathbf{4 5})^{\mathbf{0}}\right)_{s}$ shell with different extent of delaminations

\subsubsection{Antisymmetric vs symmetric lamination}

In case of undamaged shells $(c / a=0)$, on comparing two layered antisymmetric laminates $\left(0^{0} / 90^{0}\right.$ and $\left.+45^{\circ} /-45^{\circ}\right)$ with three layered symmetric laminates $\left(0^{0} / 90^{\circ} / 0^{0}\right.$ and $\left.+45^{\circ} /-45^{0} /+45^{\circ}\right)$, it is observed that symmetric stacking orders are stiffer than antisymmetric ones. This trend is true for both cross and angle ply shells. In the same tune four layered symmetric laminate $\left(0^{0} / 90^{\circ}\right)_{s}$ exhibits relatively superior performance than four layered antisymmetric one $\left(0^{0} / 90^{0}\right)_{2}$. But for angle ply shells, four layered antisymmetric lamination $\left(+45^{0} /-45^{0}\right)_{2}$ shows $8.56 \%$ lesser deflection value than that for four layered symmetric lamination $\left(+45^{0} /-45^{0}\right)_{s}$ and hence in this case four layered antisymmetric lamination is a better choice.

From the results of Table 4, it is very interesting to note that among delaminated two layered antisymmetric $\left(0^{\circ} / 90^{\circ}\right.$ and $\left.+45^{0} /-45^{0}\right)$ and three layered symmetric laminates $\left(0^{0} / 90^{\circ} / 0^{0}\right.$ and $\left.+45^{0} /-45^{0} /+45^{0}\right)$, symmetric laminates yield less deflection compared to antisymmetric ones with extent of delamination ratio $c / a=0.25$ to 0.5 , but the above trend reverses when the delaminated area increases up to $c / a=0.75$. It is also noted, comparing four layered antisymmetric $\left(0^{\circ} / 90^{\circ}\right)_{2}$ and symmetric $\left(0^{0} / 90^{\circ}\right)_{s}$ cross-plies, that antisymmetric stacking sequences show higher stiffness and exhibit $47.22 \%$ and $22.86 \%$ lesser deflection value than corresponding symmetric ones with extent of delamination ratio $c / a=0.25$ and 0.5 respectively, but if delamination zone is greater in size, symmetric cross ply laminates show better performances than antisymmetric ones. Three layered symmetric angle ply laminate $\left(+45^{0} /-45^{0} /+45^{0}\right)$ with extent of delaminated area $c / a=0.25$ proves to be better choice than two layered antisymmetric one $\left(+45^{0} /-45^{\circ}\right)$, but as the extent of delamination damage area is taken larger in size from $c / a=0.5$ to 0.75 , two layered antisymmetric laminates turn out better than three layered symmetric ones. On analyzing the maximum deflection of four layered antisymmetric and symmetric angle ply shells, mixed performance is observed with increase in extent of delamination damage zone.

Symmetric laminates are better choices for almost all extents of delamination among undamaged shell category but, it is difficult to conclude regarding the relative behaviour of antisymmetric and symmetric stacking orders for delaminated shells.

\subsubsection{Effect of increasing the number of layers}

In order to study the effect of increase of number of layers on maximum transverse downward deflection, comparative study is done for both undamaged and damaged shells in this present paper. When we compare two layered $\left(0^{0} / 90^{\circ}\right)$ and four layered $\left(0^{0} / 90^{\circ}\right)_{2}$ antisymmetric cross plies, it is seen that increase in number of plies has positive effect in decreasing the deflection values only in case of undamaged shells and for delaminated shells with $c / a=0.25$, while in rest of the cases deflection increases with increase in number of laminae. Such trend is also true for two layered antisymmetric $\left(+45^{0} /-45^{0}\right)$ and four layered antisymmetric $\left(+45^{0} /-45^{0}\right)_{2}$ angle ply laminations. Comparison among three layered symmetric $\left(0^{0} / 90^{\circ} / 0^{\circ}\right)$ and four 
layered symmetric $\left(0^{0} / 90^{\circ}\right)_{s}$ cross ply shells is also done and it is noticed that deflections decrease with increase in number of layers only in case of undamaged shells and damaged shells with $c / a=0.75$. But increase in number of layers has reverse effect on delaminated shells with extent of damaged area $c / a=0.25$ to 0.5 . It is also observed, for three layered and four layered angle plies that although increase in number of plies has a positive effect among undamaged and damaged shells with $c / a=0.25$ and 0.75 , but it has the opposite effect on damaged shells with $c / a=0.5$.

This observation leads to an important conclusion that for undamaged shells greater number of plies is always preferred but for damaged ones one cannot conclude confidently whether the number of plies shall be maintained less or more in number for better performance. Case specific study has to be carried out.
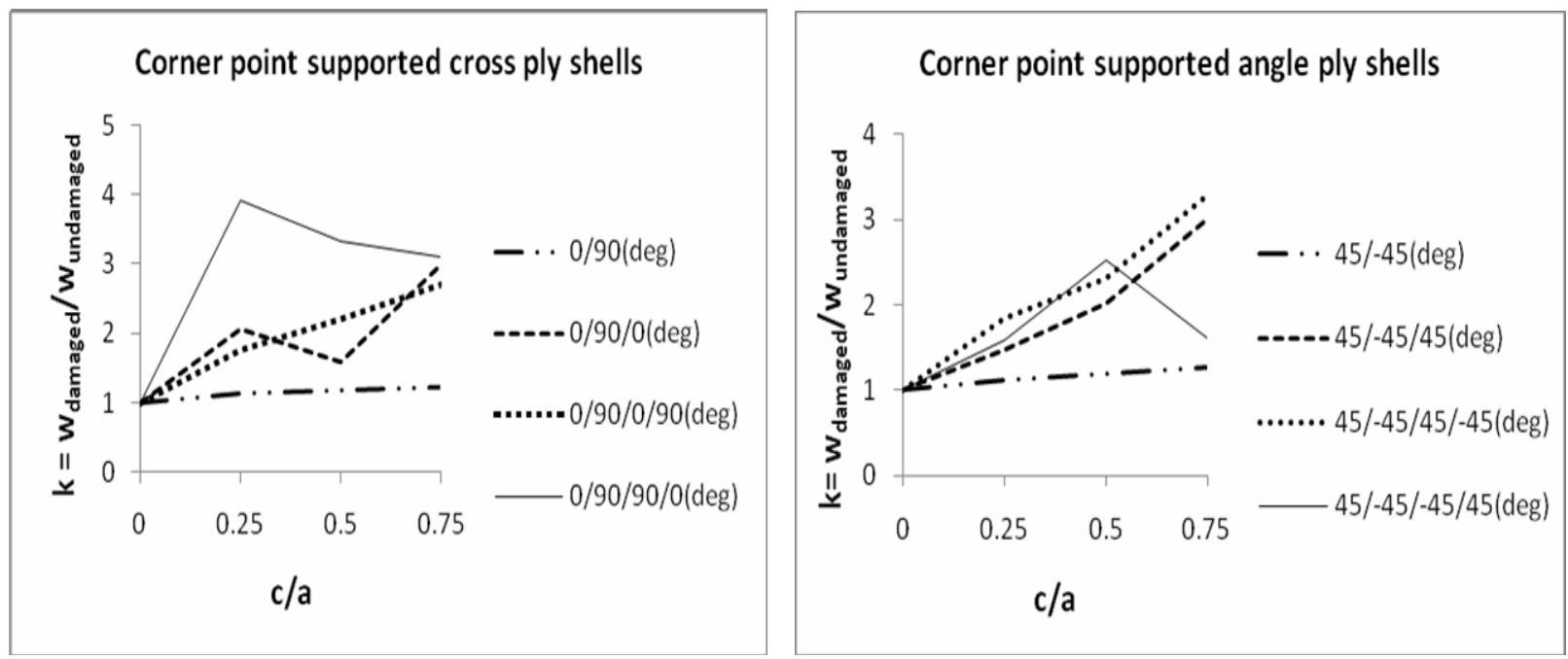

Figure 6. Graphical variation of k with different extents of delaminations ( $c / a$ ) for corner point supported shells.

\subsection{Behaviour of simply supported shells under point load - Undamaged and delaminated}

The study of deflections of simply supported shells reveals that in six out of eight stacking sequences considered here (see Table 5), maximum transverse non-dimensional downward deflection increases with increase in delaminated area ( $c / a$ ratio). However in two cases $\left(0^{0} / 90^{\circ} / 0^{\circ}\right)$ and $\left(0^{0} / 90^{\circ}\right)_{s}$ deflection value initially increases with increase in $c / a$ ratio but afterwards it decreases. Reason behind this behaviour may be understood by examining Figure 7. It is clear from the figure that although the maximum deflection does not increases with increase in $c / a$ ratio beyond 0.5 as the shell surface taken as a whole undergoes thorough change in the nature of the deflection contours and the average deflection of the area affected by delamination damage increases although the peak value undergoes a decrease. The shell suffers a substantial loss of stiffness. In Figure 8, variation of $\mathrm{k}$ with $c / a$ is plotted for cross ply and angle ply shells.

\subsubsection{Cross ply vs angle ply shell}

When undamaged cross ply and angle ply shells are compared keeping the number of layers equal in both the cases, then maximum deflection for angle ply shells are found to be less than the cross ply ones under centrally applied concentrated load. For example on comparing $\left(+45^{\circ} /-45^{\circ}\right)$ and $\left(0^{0} / 90^{\circ}\right)$ laminates, it is seen that deflection value of angle ply laminate is $23.19 \%$ less than cross ply one. This is very important point of observation.

Comparing delaminated cross and angle ply shells on the same ground it is observed that, performances of angle ply shells are better than cross ply ones in almost all the cases of laminations considered here except for few isolated cases. This trend is not true for stacking sequences like $\left(+45^{0} /-45^{0} /+45^{0}\right)$ with extent of delaminated area $c / a=0.5$ to 0.75 and $\left(+45^{0} /-45^{0}\right)_{s}$ with extent of delaminated area $c / a=0.75$ where cross ply laminates show less deflection values than angle ply ones.

Systematic study of cross ply and angle ply laminates with simply supported boundary condition shows one common feature of undamaged and damaged shells that, angle ply shells are by far better choices than cross ply ones by and large. 
Table 5. Maximum transverse non-dimensional downward deflections $\left(\bar{w} \times 10^{2}\right)$ of simply supported delaminated conoidal shells under concentrated load with different laminations

\begin{tabular}{|c|c|c|c|c|}
\hline \multirow{2}{*}{ Stacking sequence } & \multicolumn{4}{|c|}{$c / a$} \\
\hline & $\mathbf{0}$ & 0.25 & 0.5 & 0.75 \\
\hline \multirow{2}{*}{$0^{\circ} / 90^{\circ}$} & -0.401 & -0.473 & -0.487 & -0.504 \\
\hline & $(0.5,0.5)$ & $(0.5,0.5)$ & $(0.5,0.5)$ & $(0.5,0.5)$ \\
\hline \multirow{2}{*}{$0^{\circ} / 90^{\circ} / 0^{\circ}$} & -0.233 & -0.616 & -0.369 & -0.469 \\
\hline & $(0.5,0.5)$ & $(0.5,0.5)$ & $(0.5,0.5)$ & $(0.5,0.5)$ \\
\hline \multirow{2}{*}{$+45^{\circ} /-45^{\circ}$} & -0.308 & -0.359 & -0.380 & -0.401 \\
\hline & $(0.5,0.5)$ & $(0.5,0.5)$ & $(0.5,0.5)$ & $(0.5,0.5)$ \\
\hline \multirow{2}{*}{$+45^{\circ} /-45^{\circ} /+45^{\circ}$} & -0.199 & -0.356 & -0.465 & -0.587 \\
\hline & $(0.5,0.5)$ & $(0.5,0.5)$ & $(0.5,0.5)$ & $(0.5,0.5)$ \\
\hline \multirow{2}{*}{$\left(0^{\circ} / 90^{\circ}\right)_{2}$} & -0.256 & -0.537 & -0.700 & -0.848 \\
\hline & $(0.5,0.5)$ & $(0.5,0.5)$ & $(0.5,0.5)$ & $(0.5,0.5)$ \\
\hline \multirow{2}{*}{$\left(0^{\circ} / 90^{\circ}\right)_{\mathrm{S}}$} & -0.225 & -1.317 & -1.525 & -0.587 \\
\hline & $(0.5,0.5)$ & $(0.5,0.5)$ & $(0.5,0.5)$ & $(0.5,0.5)$ \\
\hline \multirow{2}{*}{$\left(+45^{\circ} /-45^{\circ}\right)_{2}$} & -0.177 & -0.445 & -0.543 & -0.645 \\
\hline & $(0.5,0.5)$ & $(0.5,0.5)$ & $(0.5,0.5)$ & $(0.5,0.5)$ \\
\hline \multirow{2}{*}{$\left(+45^{\circ} /-45^{\circ}\right)_{\mathrm{S}}$} & -0.181 & -0.361 & -0.517 & -0.782 \\
\hline & $(0.5,0.5)$ & $(0.5,0.5)$ & $(0.5,0.5)$ & $(0.5,0.5)$ \\
\hline
\end{tabular}

Note: $E_{11}=25 E_{22}, G_{12}=G_{13}=0.5 E_{22}, G_{23}=0.2 E_{22}, v_{12}=0.25, a / b=1, c=d, a / h=100, h l / h h=0.25$.

Values in the parentheses indicate the location $(\bar{x}=x / a, \bar{y}=y / b)$ of maximum downward deflection in each case.

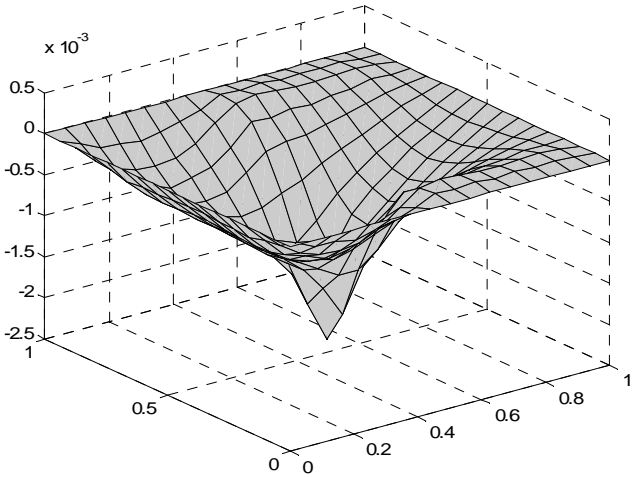

$\left(0^{0} / 90^{0} / 0^{0}\right), \mathbf{c} / \mathbf{a}=0$

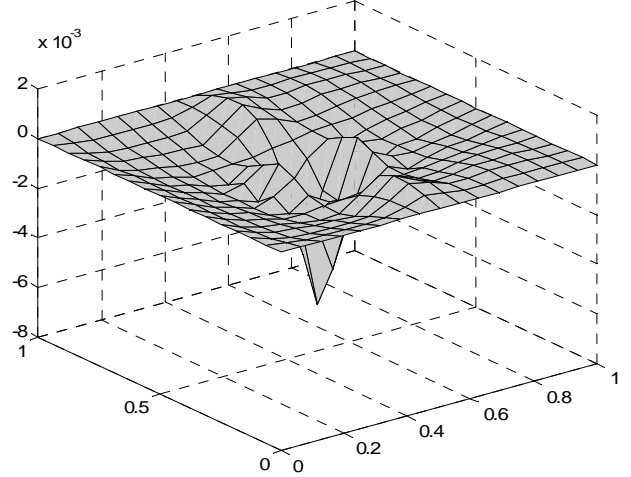

$\left(0^{0} / 90^{0} / 0^{0}\right), \mathrm{c} / \mathrm{a}=0.25$ 


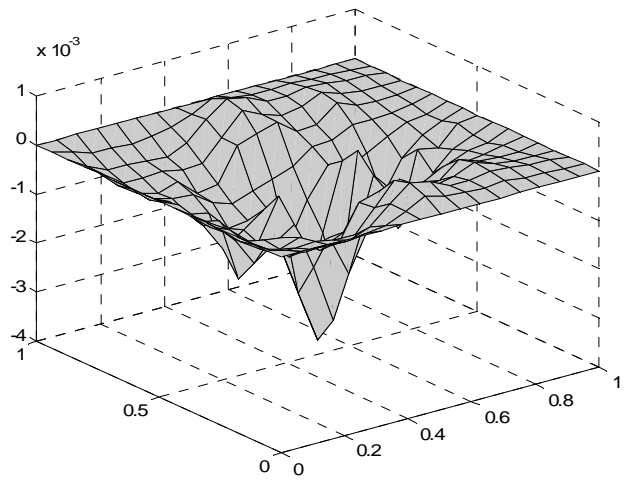

$\left(0^{0} / 90^{0} / 0^{0}\right), \mathrm{c} / \mathrm{a}=0.5$

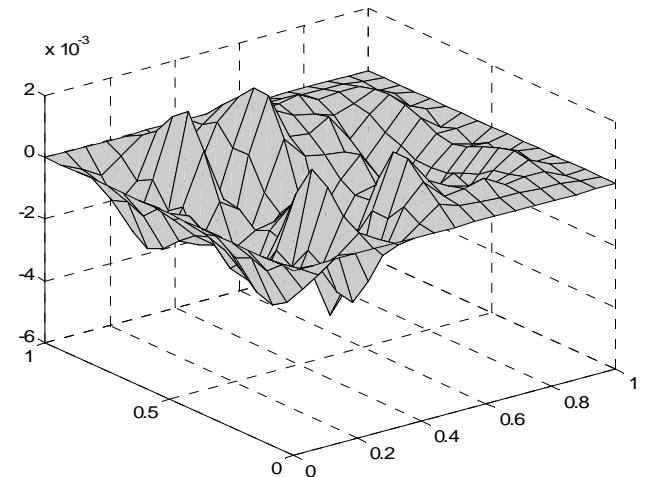

$\left(0^{0} / 90^{0} / 0^{0}\right), \mathrm{c} / \mathrm{a}=\mathbf{0 . 7 5}$

Figure 7. Deflection profile of simply supported $\left(0^{0} / \mathbf{9 0}^{\mathbf{0}} / \mathbf{0}^{\mathbf{0}}\right)$ shell with different extent of delaminations

\subsubsection{Antisymmetric vs symmetric lamination}

Among undamaged shells, if we compare antisymmetric and symmetric laminations, it is noticed that stiffness of symmetric laminates is more than antisymmetric laminates. This fact is true, for both cross ply and angle ply shells. But for four layered antisymmetric and symmetric angle ply shells this trend is not true and stiffness of antisymmetric laminate is found more than the symmetric one.

It is seen that damaged antisymmetric and symmetric cross plies show mixed relative performance as the extent of damaged area increases. This clearly indicates that no unified conclusion can be drawn about delaminated shells regarding their relative behaviour. For damaged angle ply shells also, relative performances of two layered antisymmetric $\left(+45^{0} /-45^{0}\right)$ and three layered symmetric $\left(+45^{0} /-45^{0} /+45^{0}\right)$ shells and that of four layered antisymmetric $\left(+45^{0} /-45^{0}\right)_{2}$ and symmetric $\left(+45^{0} /-45^{0}\right)_{s}$ are not unified in nature. The area of damage interacts in a complex way with the stacking sequences so that no specific conclusion can be arrived at.

This observation clearly shows the fact that, for undamaged shells symmetric laminates turn out as better choices than the antisymmetric one in most of the cases of laminations considered here, while it is difficult to give any particular judgment regarding the corresponding behaviour of delaminated shells.
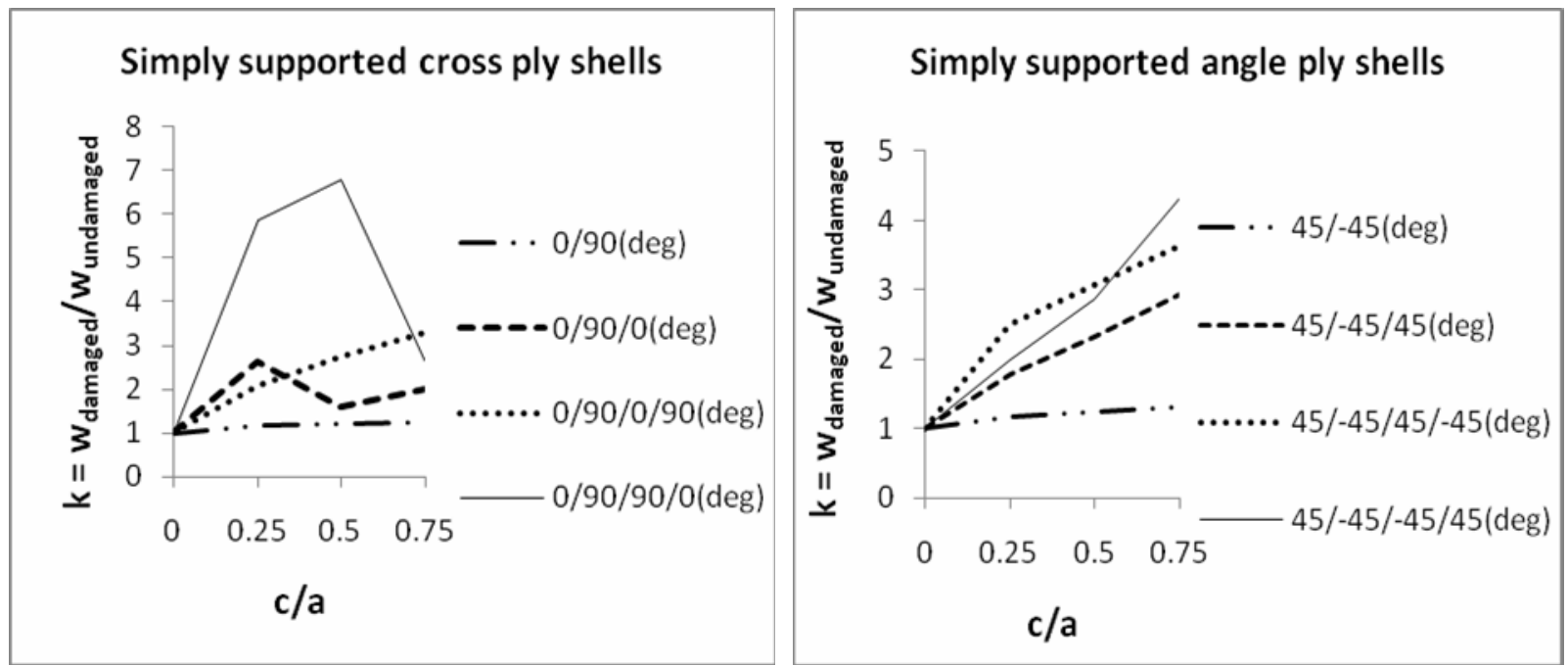

Figure 8. Graphical variation of $\mathrm{k}$ with different extents of delaminations $(c / a)$ for simply supported shells.

\subsubsection{Effect of increasing the number of layers}

For both cross and angle ply shells when antisymmetric (two and four layered) and symmetric (three and four layered) stacking orders are individually observed it is found that the deflection values decrease as the number of plies increase for undelaminated 
configuration. For example among undamaged cross ply antisymmetric laminates, when $\left(0^{0} / 90^{\circ}\right)$ and $\left(0^{0} / 90^{\circ}\right)_{2}$ laminates are compared, then it is found that increase in number of layers decreases deflection value by $36.15 \%$.

From systematic investigation of results displayed in Table-5, it is noted that the above discussed behaviour reverses completely for delaminated shells and deflection values increase with increase in number of plies under point load.

From the above discussion an important difference between behaviour of undamaged and delaminated shells is noted, that increase in number of layers has positive effect on the deflection value in case of undamaged shells, while it has reverse effect for delaminated shells.

4.3 Behaviour of clamped shells under point load - Undamaged and delaminated

Maximum transverse non-dimensional downward deflection for clamped boundary conditions under concentrated load is shown in Table 6. From the observation of results monotonic increase in deflection with increase in $c / a$ ratio is noted. If $\left(+45^{0} /-45^{0}\right)$ laminate is taken as an example then, deflection values are $19.21 \%, 25.76 \%$ and $27.51 \%$ more for $c / a=0.25,0.5$ and 0.75 respectively with respect to the corresponding deflection value of undelaminated shell. Only in two cases of lamination $\left(0^{0} / 90^{\circ} / 0^{\circ}\right)$ and $\left(0^{0} / 90^{\circ}\right)_{s}$ decrease in deflection is observed as the area of delamination damage increases from $c / a=0.25$ to 0.75 and from $c / a=0.5$ to 0.75 respectively. Behaviour of these exceptional cases becomes more clear from the study of deflection profile given in Figure 9. It is seen that although reduction in maximum transverse deflection occurs as the size of delamination damage grows, but the overall or average deflection of the shell increases many times as compared to the undelaminated shells. Again for $\left(0^{\circ} / 90^{\circ}\right)$ lamination the maximum deflection value remains somewhat non- responsive to any change in delaminated area from $c / a=0.5$ to $c / a=0.75$. For better understanding graphical variation of $\mathrm{k}$ with extent of delamination $(c / a)$ is given in Figure 10, for both cross and angle ply shells.

Table 6. Maximum transverse non-dimensional downward deflections $\left(\bar{w} \times 10^{2}\right)$ of clamped delaminated conoidal shells under concentrated load with different laminations

\begin{tabular}{ccccc}
\hline \multirow{2}{*}{ Stacking sequence } & \multicolumn{5}{c}{$\boldsymbol{c} / \boldsymbol{a}$} \\
\cline { 2 - 5 } & $\mathbf{0}$ & $\mathbf{0 . 2 5}$ & $\mathbf{0 . 5}$ & $\mathbf{0 . 7 5}$ \\
\hline \multirow{2}{*}{$0^{\circ} / 90^{\circ}$} & -0.254 & -0.322 & -0.329 & -0.329 \\
& $(0.5,0.5)$ & $(0.5,0.5)$ & $(0.5,0.5)$ & $(0.5,0.5)$ \\
& -0.122 & -0.484 & -0.233 & -0.095 \\
$+45^{\circ} / 0^{\circ}$ & $(0.5,0.5)$ & $(0.5,0.5)$ & $(0.5,0.5)$ & $(0.5,0.5)$ \\
& -0.229 & -0.273 & -0.288 & -0.292 \\
$+45^{\circ} /-45^{\circ} /+45^{\circ}$ & $(0.5,0.5)$ & $(0.5,0.5)$ & $(0.5,0.5)$ & $(0.5,0.5)$ \\
& -0.159 & -0.299 & -0.378 & -0.429 \\
$\left(0^{\circ} / 90^{\circ}\right)_{2}$ & $(0.5,0.5)$ & $(0.5,0.5)$ & $(0.5,0.5)$ & $(0.5,0.5)$ \\
& -0.144 & -0.399 & -0.537 & -0.583 \\
$\left(0^{\circ} / 90^{\circ}\right)_{\mathrm{S}}$ & $(0.5,0.5)$ & $(0.5,0.5)$ & $(0.5,0.5)$ & $(0.5,0.5)$ \\
& -0.118 & -1.151 & -1.374 & -0.075 \\
$\left(+45^{\circ} /-45^{\circ}\right)_{2}$ & $(0.5,0.5)$ & $(0.5,0.5)$ & $(0.5,0.5)$ & $(0.5,0.5)$ \\
& -0.144 & -0.393 & -0.459 & -0.492 \\
$\left(+45^{\circ} /-45^{\circ}\right)_{\mathrm{S}}$ & $(0.5,0.5)$ & $(0.5,0.5)$ & $(0.5,0.5)$ & $(0.5,0.5)$ \\
& -0.148 & -0.311 & -0.428 & -0.543 \\
\hline
\end{tabular}

Note: $E_{11}=25 E_{22}, G_{12}=G_{13}=0.5 E_{22}, G_{23}=0.2 E_{22}, v_{12}=0.25, a / b=1, c=d, a / h=100, h l / h h=0.25$.

Values in the parentheses indicate the location $(\bar{x}=x / a, \bar{y}=y / b)$ of maximum downward deflection in each case. 


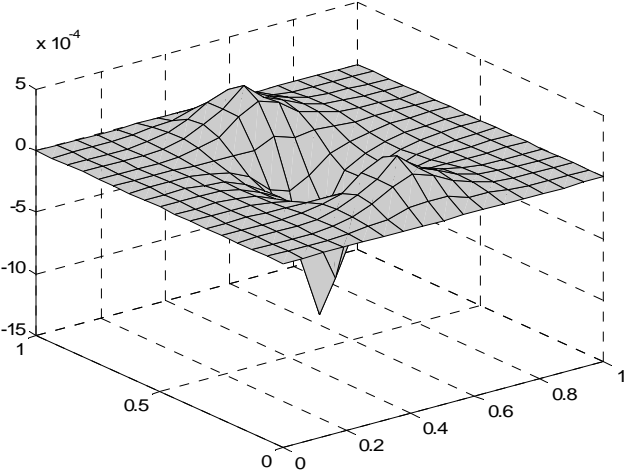

$\mathbf{0}^{0} / 90^{0} / \mathbf{0}^{0}, \mathrm{c} / \mathbf{a}=\mathbf{0}$

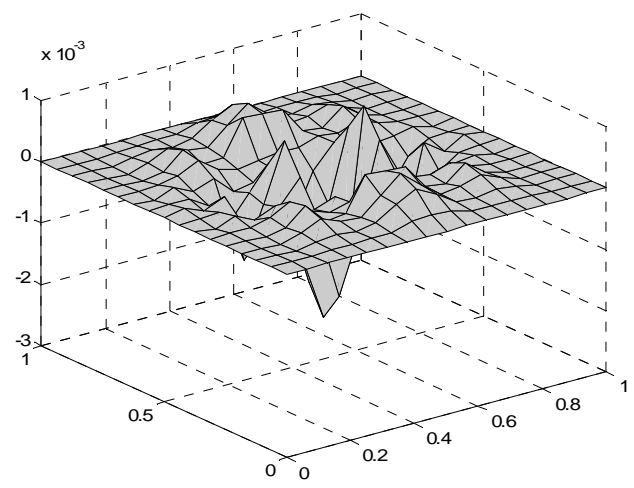

$0^{0} / 90^{0} / 0^{0}, \mathbf{c} / \mathbf{a}=0.5$

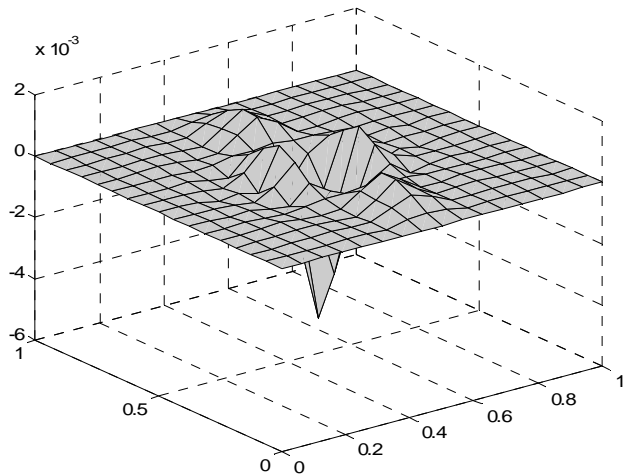

$0^{0} / 90^{0} / \mathbf{0}^{0}, \mathrm{c} / \mathbf{a}=\mathbf{0 . 2 5}$

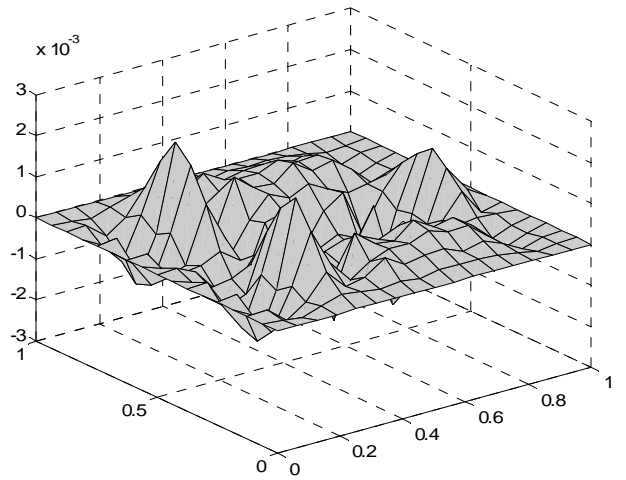

$0^{0} / 90^{0} / 0^{0}, \mathrm{c} / \mathrm{a}=0.75$

Figure 9. Deflection profile of clamped $\left(0^{0} / \mathbf{9 0}^{\mathbf{0}} / \mathbf{0}^{\mathbf{0}}\right)$ shell with different extent of delaminations

\subsubsection{Cross ply vs angle ply shells}

The authors compare two layered, three layered and four layered antisymmetric and symmetric cross ply laminates with the corresponding angle ply laminates respectively. For undamaged shells, it is observed that cross ply laminations play better roles than angle ply ones in most of the cases of laminations considered here. Whereas undamaged four layered antisymmetric cross ply and angle ply laminates yield same deflection values under centrally applied concentrated load.

Among delaminated shells, two layered angle ply shells show $15.21 \%, 12.46 \%$ and $11.24 \%$ lesser deflection value than that of corresponding two layered cross ply shells for $c / a=0.25,0.5$ and 0.75 respectively. Comparing three layered cross and angle ply shells, we find that cross ply shells turn out as better choices than angle ply ones, except when $c / a=0.25$, where angle ply laminate shows less deflection than cross ply laminate. On thorough investigation of four layered antisymmetric and symmetric cross and angle ply stacking sequences, it is observed that four layered angle ply shells are stiffer than cross ply ones, excluding case of four layered symmetric cross ply shell $\left(0^{0} / 90^{\circ}\right)_{s}$ with delamination ratio $c / a=0.75$.

Based on above observations it can be inferred that cross ply laminations are better than angle ply ones for undelaminated shells. But no such specific conclusion can be made for delaminated shells. In case of delaminated shells it may so happen that both cross and angle ply laminates can show better performance depending upon other factors like symmetry or anti-symmetry and number of layers. Hence further study is required here.

\subsubsection{Antisymmetric vs symmetric lamination}

Comparison is done between antisymmetric and symmetric undamaged shells, both for cross ply and angle ply laminations. It is noticed that symmetric stacking sequences show lesser deflection values than antisymmetric ones, for almost all the stacking sequences taken up here. But for four layered angle ply shells, symmetric laminate shows $2.77 \%$ higher deflection value than that of the corresponding antisymmetric one. This behaviour is opposite from rest of the stacking orders. 
Among delaminated shells, when two layered antisymmetric $\left(0^{\circ} / 90^{\circ}\right.$ and $\left.+45^{\circ} /-45^{\circ}\right)$ and three layered symmetric $\left(0^{0} / 90^{\circ} / 0^{0}\right.$ and $\left.+45^{0} /-45^{\circ} /+45^{0}\right)$ stacking orders are compared, behaviour of antisymmetric and symmetric laminates show arbitrary variation with increase in $c / a$ ratio, and thus it is difficult for the authors to arrive at any pin pointed conclusion. In the same tune, relative performances of four layered antisymmetric and symmetric laminates are also mixed in nature. For cross ply shells, four layered antisymmetric laminations $\left(0^{0} / 90^{\circ}\right)_{2}$ with extents of damaged area $c / a=0.25$ to 0.5 perform better than the corresponding symmetric laminations $\left(0^{0} / 90^{\circ}\right)_{s}$, but this trend does not hold good if extent of damaged zone increases up to $c / a=0.75$. For angle ply shells, four layered symmetric laminations $\left(+45^{0} /-45^{0}\right)_{s}$ show more bending stiffness than antisymmetric ones i.e. $\left(+45^{0} /-45^{0}\right)_{2}$ with $c / a=0.25$ to 0.5 . But this behaviour becomes opposite when the extent of delamination ratio $c / a$ reaches 0.75 .

Symmetric laminates yield less deflection values than the antisymmetric ones in almost all the cases of laminations considered here for undamaged shells. Among delaminated shells it is noticed that the relative performances of antisymmetric and symmetric laminates are mixed in nature and a unified conclusion cannot be drawn.

\subsubsection{Effect of increasing the number of layers}

From the results of Table 6 it is evident that in case of undamaged shells, deflection value decreases with increase in number of layers. Positive effect on deflection value by increasing the number of layers is observed in all the cases of laminations.

It is very important to note that, deflection value increases with increase in number of layers by and large for delaminated shells also. From results of Table- 6 it is clear that, if $\left(+45^{0} /-45^{0}\right)$ and $\left(+45^{0} /-45^{0}\right)_{2}$ laminates are compared, deflection values are found more by $43.95 \%, 59.37 \%$ and $68.49 \%$ for $c / a=0.25,0.5$ and 0.75 respectively with increase in number of layers. This observation is true for both antisymmetric and symmetric sequences for both cross and angle ply shells. But in one exceptional case, when $\left(0^{\circ} / 90^{\circ} / 0^{\circ}\right)$ lamination is compared with $\left(0^{\circ} / 90^{\circ}\right)$ s lamination, it is noticed that deflection value decreases with increase in number of layers with extent of delamination ratio $c / a=0.75$.

Thus it can be inferred that an engineer has to be cautious before providing more number of laminae for achieving higher bending stiffness because once delamination damage sets in, a shell surface tends to get more deteriorated if number of layers is more.
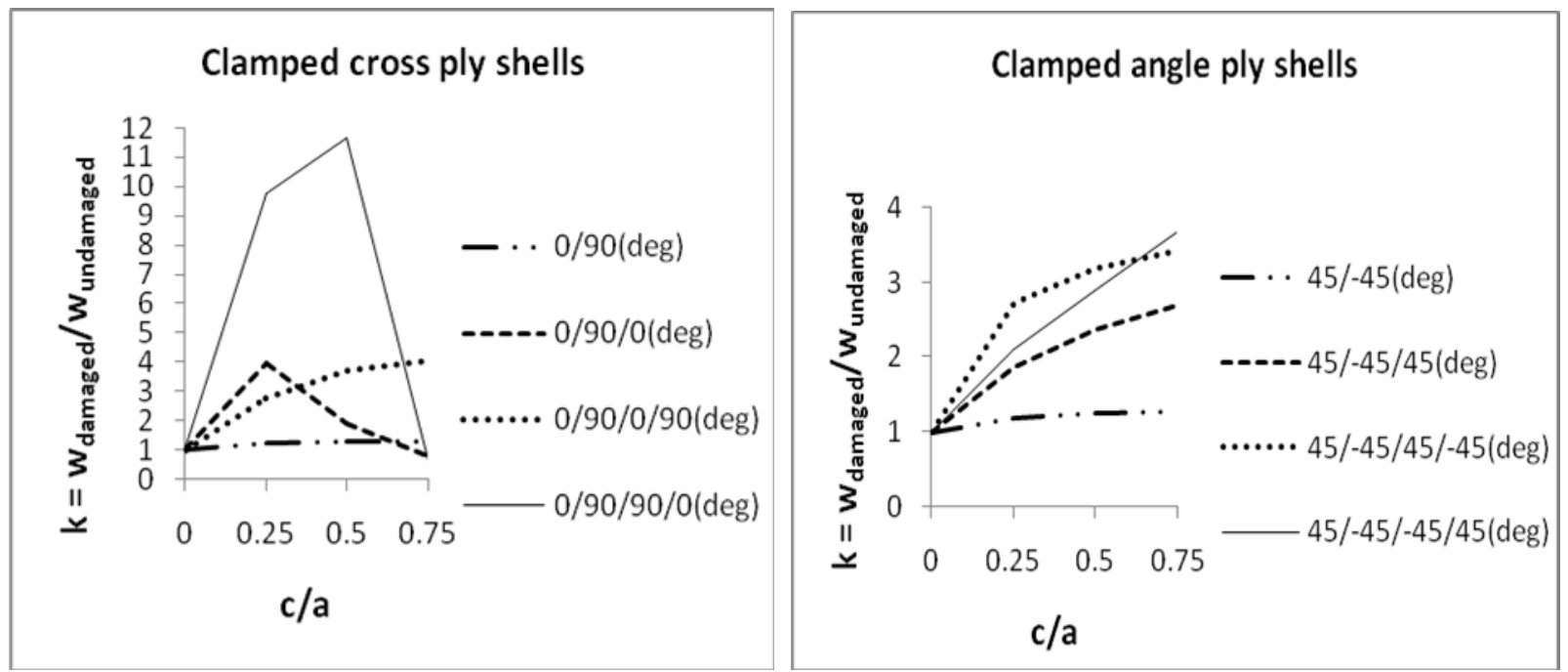

Figure 10. Graphical variation of $\mathrm{k}$ with different extents of delaminations $(c / a)$ for clamped shells.

\section{Conclusions}

The following conclusions are drawn from the present study:

1. The finite element formulation presented in this paper can be successfully applied to analyse bending problems of undelaminated and delaminated conoidal shells which is clear from the results of benchmark problems presented here. 
2. Introduction of delamination damage within a composite shell surface brings about reduction of bending stiffness which is manifested in two ways. The deflection under the load normally undergoes an increase. In some cases, however, the maximum deflection undergoes a decrease but the average deflection of delaminated zone definitely goes up.

3. For corner point supported undamaged shell, angle ply should be preferred for antisymmetric laminations while cross ply is better for symmetric ones. Interestingly for damaged shells angle ply shell exhibit consistently better performances than the cross ply one.

4. For corner point supported composite conoidal shell symmetric laminates offer better bending resistance than the antisymmetric ones without delamination, but once the surface is delaminated no unified trend is noted in behaviour. For this boundary condition an increase in number of laminae is good for undamaged shell, but for delaminated configuration such conclusion do not hold.

5. For simply supported composite conoidal shell, like the corner point supported ones, delamination damage increases the average deflection but not necessarily the maximum one. For this boundary condition symmetric laminations are better for undamaged shell but the behaviour of damaged shell shows a departure where a pin pointed conclusion cannot be made. For this boundary condition, as before, static stiffness is higher for more number of layers in the laminate for the undamaged configuration. For delaminated shell just the reverse picture is noted.

6. The behaviour of clamped composite conoidal shell in terms of average and maximum deflection, when shells are considered with increasingly greater area of damage, is same like the other two boundary conditions. Here again symmetric laminates should be preferred for undamaged shells while such a conclusion cannot be drawn for damaged ones. Here also a shell surfaces is stiffer when the number of layers is more within a given thickness when there is no damage, but once the surface is delaminated just the reverse trend is noted.

\section{Nomenclature}

$\begin{array}{ll}a, b & \text { length and width of shell in plan along beam and arch directions respectively } \\ c, d & \begin{array}{l}\text { length and width of delamination area in plan along beam and arch } \\ \text { directions respectively }\end{array} \\ {[A],[B],[D]} & \text { extension, bending extention coupling and bending stiffness matrices respectively } \\ E_{11}, E_{22} & \text { elastic moduli } \\ \{F\} & \text { force and moment resultant } \\ G_{12}, G_{13}, G_{23} & \text { shear moduli of a lamina with respect to } 1,2 \text { and } 3 \text { axes of fiber } \\ h & \text { shell thickness } \\ h h & \text { greater height of conoid } \\ h l & \text { smaller height of conoid } \\ \{\kappa\} & \text { curvature changes due to loading } \\ \kappa_{x}, \kappa_{y}, \kappa_{x y} & \text { curvatures of shell } \\ \{M\} & \text { moment vectors } \\ M_{x}, M_{y} & \text { moment resultants } \\ M_{x y} & \text { torsion resultant } \\ \{N\} & \text { force vectors } \\ N_{x}, N_{y} & \text { inplane force resultants } \\ N_{x y} & \text { inplane shear resultant } \\ P & \text { transverse concentrated load } \\ \{Q\} & \text { transverse shear force vectors } \\ Q_{x}, Q_{y} & \text { transverse shear resultants } \\ {\left[Q_{i j}\right]} & \text { elastic constant matrix } \\ R_{y} & \text { radius of shell surface along arch }(y) \text { direction } \\ R_{x y} & \text { radii of cross curvature of shell }\end{array}$


[S] stiffness matrix in transverse shear

$u, v, w \quad$ translational degrees of freedom at each node of shell element

$\alpha, \beta \quad$ rotational degrees of freedom at each node of shell element

$\{\delta\} \quad$ displacement vectors

$\{\varepsilon\} \quad$ inplane strain vectors

$\left\{\varepsilon^{0}\right\} \quad$ inplane strain vectors at the mid-surface

$\varepsilon_{x}^{0}, \varepsilon_{y}^{0}, \gamma_{x y}^{0} \quad$ inplane strains of the mid-plane

$\gamma_{x z}^{0}, \gamma_{y z}^{0} \quad$ transverse shear strains of the mid-plane

$\{\gamma\} \quad$ transverse shear strain vectors

$\left\{v_{12}\right\} \quad$ Poisson's ratio

$\xi, \eta \quad$ local natural co-ordinates of an element

$\bar{w} \quad$ non-dimensional deflection, where $\bar{w}=\left(w h^{3} E_{22} / P a^{2}\right) \times 10^{2}$

$\rho \quad$ density of material

w vertical deflection

\section{References}

Acharyya, A. K., Chakravorty, D., and Karmakar, A., 2008. Bending characteristics of delaminated composite cylindrical shells with complicated boundary conditions. International Journal of Material Research, Electronics and Electrical System, Vol. 1, No.1, pp. 11-23.

Acharyya, A. K., Chakravorty, D., and Karmakar, A., 2009a. Bending characteristics of delaminated composite cylindrical shellsa finite element approach. Journal of Reinforced Plastics and Composites, Vol. 28, No.8, pp. 965-978.

Acharyya, A. K., Chakravorty, D., and Karmakar, A., 2009b. Natural vibrations of delaminated composite clamped cylindrical shell roofs. Advances in Vibration Engineering-An International Journal, Vol.8, No.3, pp. 257-262.

Das, H., Chakravorty, D., 2007. Design aids and selection guidelines for composite conoidal shell roofs - a finite element application. Journal of Reinforced Plastic and Composites, Vol. 26, No.17, pp. 1793-1819.

Das, H., Chakravorty, D., 2008. Natural frequencies and mode shapes of composite conoids with complicated boundary conditions. Journal of Reinforced Plastic and Composites, Vol. 27, No. 3, pp. 1397-1415.

Gim, C.K., 1994. Plate finite element modeling of laminated plates, Computers \& Structures, Vol. 52, No. 1, pp. 157-168.

Krishnamurthy, K. S., Mahajan, P., and Mittal, R. K., 2001. A parametric study of the impact response and damage of laminated cylindrical composite shells. Composites Science and Technology, Vol. 61, No.12, pp. 1655-1669.

Librescu, L., and Schmidt, R., 2000. A general linear theory of laminated composite shells featuring interlaminar bonding imperfections. International Journal of Solids and Structures, Vol. 38, No.19, pp. 3355-3375.

Reddy, J. N., 1997. Mechanics of Laminated Composite Plates - Theory and Analysis.CRC Press.

Tafreshi, A., 2004a. Efficient modeling of delamination buckling in composite cylindrical shells under axial compression. Composite Structures, Vol. 64, No. 3-4, pp. 511-520.

Tafreshi, A., 2004b. Delamination buckling and postbuckling in composite cylindrical shells under external pressure. Thin-Walled Structures, Vol. 42, No. 10, pp. 1379-1404.

Biographical notes

Mrs Suman Kumari is a research scholar in Civil Engineering Department, Jadavpur University, Kolkata, India. Her field of specialization is Structural Engineering. She has teaching experience of approximately 3 years.

Dr. Dipankar Chakravorty is working as a Professor in Civil Engineering Department, Jadavpur University, Kolkata, India. He is engaged in teaching and research activities since last 19 years. He is also actively engaged in various project works. He has done his research in the field of bending, free and forced vibration of laminated composite shells. He has published 26 papers in reputed international journals apart from a number of other papers in international conferences.

Received December 2009

Accepted March 2010

Final acceptance in revised form May 2010 